\title{
Basolateral Amygdala to Orbitofrontal Cortex Projections Enable Cue-Triggered Reward Expectations
}

\author{
Nina T. Lichtenberg, ${ }^{1}$ Zachary T. Pennington, ${ }^{1}$ Sandra M. Holley, ${ }^{2}$ Venuz Y. Greenfield, ${ }^{1}$ Carlos Cepeda, ${ }^{2}$ \\ Michael S. Levine, ${ }^{2,3}$ and Kate M. Wassum ${ }^{1,3}$ \\ ${ }^{1}$ Department of Psychology and ${ }^{2}$ Intellectual and Developmental Disabilities Research Center, Semel Institute for Neuroscience and Human Behavior, \\ David Geffen School of Medicine, and ${ }^{3}$ Brain Research Institute, University of California Los Angeles, Los Angeles, California 90095
}

To make an appropriate decision, one must anticipate potential future rewarding events, even when they are not readily observable. These expectations are generated by using observable information (e.g., stimuli or available actions) to retrieve often quite detailed memories of available rewards. The basolateral amygdala (BLA) and orbitofrontal cortex (OFC) are two reciprocally connected key nodes in the circuitry supporting such outcome-guided behaviors. But there is much unknown about the contribution of this circuit to decision making, and almost nothing known about the whether any contribution is via direct, monosynaptic projections, or the direction of information transfer. Therefore, here we used designer receptor-mediated inactivation of $\mathrm{OFC} \rightarrow \mathrm{BLA}$ or $\mathrm{BLA} \rightarrow \mathrm{OFC}$ projections to evaluate their respective contributions to outcome-guided behaviors in rats. Inactivation of BLA terminals in the OFC, but not OFC terminals in the BLA, disrupted the selective motivating influence of cue-triggered reward representations over reward-seeking decisions as assayed by Pavlovian-to-instrumental transfer. BLA $\rightarrow 0 F C$ projections were also required when a cued reward representation was used to modify Pavlovian conditional goal-approach responses according to the reward's current value. These projections were not necessary when actions were guided by reward expectations generated based on learned action-reward contingencies, or when rewards themselves, rather than stored memories, directed action. These data demonstrate that BLA $\rightarrow 0 F C$ projections enable the cue-triggered reward expectations that can motivate the execution of specific action plans and allow adaptive conditional responding.

Key words: chemogenetics; devaluation; DREADD; hM4Di; Pavlovian-to-instrumental transfer; reinstatement

\section{Significance Statement}

Deficits anticipating potential future rewarding events are associated with many psychiatric diseases. Presently, we know little about the neural circuits supporting such reward expectation. Here we show that basolateral amygdala to orbitofrontal cortex projections are required for expectations of specific available rewards to influence reward seeking and decision making. The necessity of these projections was limited to situations in which expectations were elicited by reward-predictive cues. These projections therefore facilitate adaptive behavior by enabling the orbitofrontal cortex to use environmental stimuli to generate expectations of potential future rewarding events.

\section{Introduction}

Appropriate decision making requires the accurate anticipation of potential rewarding outcomes. Often these rewards are not

Received Feb. 20, 2017; revised July 10, 2017; accepted July 20, 2017.

Author contributions: N.T.L., Z.T.P., S.M.H., C.C., M.S.L., and K.M.W. designed research; N.T.L., Z.T.P., S.M.H., and V.Y.G. performed research; N.T.L., S.M.H., and K.M.W. analyzed data; N.T.L., Z.T.P., S.M.H., C.C., and K.M.W. wrote the paper.

This work was supported by National Institutes of Health Grant DA035443, University of California at Los Angeles Faculty Career Development Award to K.M.W., National Institutes of Health Training Grant DA024635, the Dr. Ursula Mandel Scholarship, and a University of California, Los Angeles Graduate Research Mentorship fellowship to N.T.L. We thank Drs. Alicia Izquierdo, Melissa Malvaez, and Ashleigh Morse for helpful discussions regarding these data. The authors declare no competing financial interests.

Correspondence should be addressed to Dr. Kate M. Wassum, Department of Psychology, University of California, Los Angeles, 1285 Franz Hall, Box 951563 Los Angeles, CA 90095. E-mail: kwassum@ucla.edu. present or noticeable in the immediate environment. So one must use information that can be observed, such as the presence of stimuli or available actions, to enable the mental representation of the critical information needed to make a choice: future possible outcomes. Indeed, stored knowledge of specific stimulus-outcome or action-outcome relationships permits recollection of the detailed reward memories that facilitate the outcome expectations that influence conditional responses, reward seeking, and decision making (Balleine and Dickinson, 1998; Delamater and Oakeshott, 2007; Delamater, 2012; Fanselow and Wassum, 2015). Detailed reward predictions enable adaptive be- 
havior by allowing individuals to rapidly adjust to environmental changes and to infer the most advantageous option in novel situations. But disruptions in this process can lead to the cognitive symptoms underlying many psychiatric diseases.

The orbitofrontal cortex (OFC) and basolateral amygdala (BLA) are two identified key nodes in the circuitry supporting outcome-guided behaviors. Damage to either region causes performance deficits when specific rewarding events must be anticipated (Gallagher et al., 1999; Blundell et al., 2001; Pickens et al., 2003, 2005; Izquierdo et al., 2004; Wellman et al., 2005; Machado and Bachevalier, 2007; Ostlund and Balleine, 2007b, 2008; Johnson et al., 2009; West et al., 2011; Jones et al., 2012; Scarlet et al., 2012; Rhodes and Murray, 2013; Malvaez et al., 2015). These regions share dense and reciprocal direct connections (Carmichael and Price, 1995; Price, 2007) and associative encoding in one region has generally been shown to be altered by lesions of the other (Schoenbaum et al., 2003; Saddoris et al., 2005; Hampton et al., 2007; Rudebeck et al., 2013, 2017; Lucantonio et al., 2015). The unique contribution of each region is still a matter of debate, but there is some evidence to suggest that the BLA might acquire reward representations, whereas the OFC is more important for using this information to generate the expectations that guide action (Pickens et al., 2003; Wellman et al., 2005; Wassum et al., 2009; Jones et al., 2012; Parkes and Balleine, 2013; Takahashi et al., 2013; Gore et al., 2015). The OFC may be especially needed when critical determining elements of future possible states (e.g., potential rewarding outcomes) are not readily observable (Wilson et al., 2014; Bradfield et al., 2015; Schuck et al., 2016). But understanding of BLA-OFC function is limited by the fact that the contribution of direct, monosynaptic projections and the direction of information transfer are unknown. Therefore, here we used designer receptor-mediated inactivation of $\mathrm{OFC} \rightarrow \mathrm{BLA}$ or BLA $\rightarrow$ OFC monosynaptic projections to evaluate their respective contributions to the ability to use detailed reward expectations to influence reward seeking and decision making. Follow-up tests focused on the specific contribution of BLA $\rightarrow$ OFC projections.

\section{Materials and Methods}

\section{Subjects}

Subjects were male, Long-Evans rats ( $n=60$ total, Charles River Laboratories) weighing between 300 and $390 \mathrm{~g}$ (age $\sim 3$ months) at the beginning of the experiment. Rats were pair housed and handled for $\sim 5 \mathrm{~d}$ before the onset of the experiment. Training and testing took place during the dark phase of the 12:12 h reverse dark/light cycle. Rats had ad libitum access to filtered tap water in the home cage and were maintained on a food-restricted schedule whereby they received 12-14 g of their maintenance diet (Lab Diet) daily to maintain 85\%-90\% free-feeding body weight. All procedures were conducted in accordance with the National Institutes of Health Guide for the care and use of laboratory animals and approved by the University of California, Los Angeles Institutional Animal Care and Use Committee.

\section{Viral constructs}

Transduction of OFC or BLA neurons with the inhibitory designer receptor exclusively activated by designer drug (DREADD) hM4Di was achieved with an adeno-associated virus (AAV) driving the hM4Di-mCherry sequence under the human synapsin promoter (AAV8-hSyn-hM4Di$m$ Cherry, viral concentration $7.4 \times 10^{12} \mathrm{vg} / \mathrm{ml}$; University of North Carolina Vector Core, Chapel Hill, NC). A virus lacking the hM4Di DREADD gene (AAV8-hSyn-mCherry; viral concentration $4.6 \times 10^{12}$ $\mathrm{vg} / \mathrm{ml}$; University of North Carolina Vector Core) was used as a control. For ex vivo electrophysiology experiments, hM4Di and the excitatory opsin, channelrhodopsin (ChR2; AAV5-CaMKII-ChR2-EYFP; viral concentration $6.2 \times 10^{12} \mathrm{vg} / \mathrm{ml}$; University of North Carolina Vector Core), were coexpressed in either the OFC or BLA using a mixture of both viruses. A separate control group received only the ChR2 virus. Behavioral testing began between 6 and 8 weeks after viral injection to allow anterograde transmission and robust axonal expression in terminal regions.

\section{Surgical procedures}

Standard aseptic surgical procedures were used under isoflurane anesthesia ( $5 \%$ induction, $1 \%-2 \%$ maintenance). Bilateral virus injections were made via 33-gauge, stainless-steel injectors inserted into either the BLA (anteroposterior $-3.0 \mathrm{~mm}$, mediolateral $\pm 5.1 \mathrm{~mm}$, dorsoventral -8.0 or $-8.5 \mathrm{~mm}$ relative to bregma) or OFC (anteroposterior 3.0 $\mathrm{mm}$, mediolateral $\pm 3.2 \mathrm{~mm}$, dorsoventral $-6.0 \mathrm{~mm}$ ). Viruses were infused in a volume of 0.6 (BLA) or 0.8 (OFC) $\mu$ l per hemisphere at a flow rate of $0.1 \mu \mathrm{l} / \mathrm{min}$. Injectors were left in place for an additional $10 \mathrm{~min}$ to ensure adequate diffusion and to minimize viral spread up the injector tract. For rats in the behavioral experiments, during the same surgery, 22-gauge, stainless-steel guide cannulae (Plastics One) were implanted bilaterally targeted $1 \mathrm{~mm}$ above the BLA (anteroposterior $-3.0 \mathrm{~mm}$, mediolateral $\pm 5.1 \mathrm{~mm}$, dorsoventral $-7.0 \mathrm{~mm}$ ) for the OFC viral injection groups, or the OFC (anteroposterior $+3.0 \mathrm{~mm}$, mediolateral \pm 3.2 $\mathrm{mm}$, dorsoventral $-5.0 \mathrm{~mm}$ ) for groups receiving viral injections into the BLA. A nonsteroidal anti-inflammatory agent was administered preoperatively and postoperatively to minimize pain and discomfort. Following surgery, rats were individually housed and allowed to recover for $\sim 16 \mathrm{~d}$ before the onset of any behavioral training.

\section{Behavioral training}

Training and testing took place in a set of 16 Med Associates operant chambers, described previously (Wassum et al., 2016).

Pavlovian training. Each of the 8 daily sessions consisted of 8 tone $(1.5 \mathrm{kHz})$ and 8 white noise conditional stimulus (CS) presentations (75 db, 2-min duration), during which either sucrose solution (20\%, $0.1 \mathrm{ml} /$ delivery) or grain pellets ( $45 \mathrm{mg}$; Bio-Serv) were delivered on a 30 -s random-time schedule into the food-delivery port, resulting in an average of 4 stimulus-reward pairings per trial. For half the subjects, tone was paired with sucrose and noise with pellets, with the other half receiving the opposite arrangement. CSs were delivered pseudo-randomly with a variable $2-4 \mathrm{~min}$ intertrial interval (mean $3 \mathrm{~min}$ ). Entries into the fooddelivery port were recorded for the entire session. Comparison of anticipatory entries during the CS-probe periods (interval between CS onset and first reward) with entries during baseline periods ( 2 min period before CS onset) provided a measure of Pavlovian conditioning.

Instrumental training. Rats were then given $11 \mathrm{~d}$ of instrumental training, receiving 2 separate training sessions per day: one with the lever to the left of the food-delivery port and one with the right lever. Each action was reinforced with a different outcome, either grain pellets or sucrose solution (counterbalanced with respect to the Pavlovian contingencies). Each session terminated after 30 outcomes had been earned or $30 \mathrm{~min}$ had elapsed. Actions were continuously reinforced on the first day and then escalated to a random-ratio-20 schedule. The rate of responding on each lever was measured throughout training.

\section{Pavlovian-to-instrumental transfer test}

Four groups of subjects received Pavlovian-to-instrumental transfer (PIT) tests: $\mathrm{OFC}_{\mathrm{hM} 4 \mathrm{Di}} \rightarrow \mathrm{BLA}(n=10), \mathrm{BLA}_{\mathrm{hM} 4 \mathrm{Di}} \rightarrow \mathrm{OFC}(n=10), \mathrm{OFC}_{\text {mCherry }} \rightarrow$ $\mathrm{BLA}(n=11)$, and BLA $\mathrm{mCherry} \rightarrow \mathrm{OFC}(n=12)$. On the day before each PIT test, rats were given a single 30 -min extinction session during which both levers were available, but pressing was not reinforced to establish a low level of responding. Each rat was given 2 PIT tests: one following infusion of vehicle and one following infusion of the otherwise inert hM4Di ligand, clozapine-n-oxide (CNO), into the BLA $\left(\mathrm{OFC}_{\mathrm{hM} 4 \mathrm{Di}} \rightarrow \mathrm{BLA}\right.$ and $\mathrm{OFC}_{\mathrm{mCherry}} \rightarrow \mathrm{BLA}$ groups $)$ or $\mathrm{OFC}\left(\mathrm{BLA}_{\mathrm{hM} 4 \mathrm{Di}} \rightarrow\right.$ OFC and BLA mCherry $_{\rightarrow}$ OFC groups). Test order was counterbalanced across subjects. During each PIT test, both levers were continuously present, but pressing was not reinforced. After 5 min of lever-pressing extinction, each 2-min CS was presented separately 4 times each in pseudorandom order, separated by a fixed, 4 -min intertrial interval. No rewards were delivered during CS presentation. The 2-min period before each CS presentation served as the baseline. Rats were given 2 retraining 
sessions for each instrumental association (2 sessions/d for $2 \mathrm{~d}$ ) and 1 Pavlovian retraining session in between PIT tests.

\section{Outcome-specific devaluation test}

Following training, a second cohort of $\mathrm{BLA}_{\mathrm{hM} 4 \mathrm{Di}} \rightarrow \mathrm{OFC}$ rats $(n=9)$ was given a series of two outcome-specific devaluation tests. Before each test, rats were given $1-\mathrm{h}$, unlimited access to either sucrose solution or food pellets in pre-exposed feeding chambers such that the prefed reward would become devalued, whereas the other reward would remain valued. Immediately after this prefeeding, rats received infusions of either vehicle or CNO into the OFC and were then tested. The test consisted of two phases. In the first, both levers were available, and nonreinforced lever pressing was assessed for $5 \mathrm{~min}$. The levers were then retracted, which started the second, Pavlovian, test phase, in which each 2-min CS was presented, without accompanying reward, separately 2 times each in alternating order, separated by a fixed, 4-min intertrial interval. The 2-min period before each CS presentation served as the baseline. Successful devaluation of the earned outcome was confirmed by post test consumption of each food reward, in which rats ate significantly less of the devalued reward type (mean \pm SEM, $1.81 \pm 0.43 \mathrm{~g}$ ) relative to the valued reward $\left(5.38 \pm 0.7 ; t_{(17)}=4.05, p=0.0008\right)$.

After the first test, rats remained in their home cage for $2 \mathrm{~d}$ and were then given 2 retraining sessions for each instrumental association ( 2 sessions/d for $2 \mathrm{~d}$ ) and 1 Pavlovian retraining session, before the second outcome-specific devaluation test. For the second test, rats were prefed on the opposite food reward (e.g., pellets if sucrose had been pre fed on Test 1) and infused with the opposite drug (e.g., CNO, if they had previously received vehicle). Thus, each rat experienced 2 devaluation tests to allow a within-subject drug-treatment design: one following vehicle and one following CNO infusion, counterbalanced for order. Because, in the absence of the hM4Di receptor, CNO itself was found to have no effect on the expression of PIT, which requires both actionoutcome and stimulus-outcome associative information, empty-vector controls were not included for this experiment in which the use of either action-outcome or stimulus-outcome associations was assessed.

\section{Outcome-specific reinstatement test}

Rats then received $4 \mathrm{~d}$ of instrumental retraining before outcome-specific reinstatement testing. On the day before each reinstatement test, rats received a $30 \mathrm{~min}$ lever-pressing extinction session. Each rat was given 2 reinstatement tests, one following intra-OFC vehicle infusion and one after CNO infusion, counterbalanced for order. Rats were given instrumental retraining in between the two reinstatement tests. During each reinstatement test, both levers were continuously present, but pressing was never reinforced. After 5 min of extinction, rewards were presented in 8 separate reward-presentation periods ( 4 sucrose, 4 pellet periods, in pseudorandom order) separated by a fixed 4 -min intertrial interval. Each reward presentation period was $2 \mathrm{~min}$ in duration and began with 2 deliveries of the appropriate reward, separated by $6 \mathrm{~s}$. The 2-min period before each reward-delivery period served as the baseline.

\section{Drugs}

For behavioral experiments, $\mathrm{CNO}$ (Tocris Bioscience) was dissolved in aCSF to $1 \mathrm{~mm}$ and was intracranially infused over $1 \mathrm{~min}$ in a volume of $0.25 \mu \mathrm{l}$ into the OFC or $0.5 \mu \mathrm{l}$ into the BLA. Injectors were left in place for at least 1 additional min to allow for drug diffusion. Behavioral testing commenced within 5-10 min following infusion. CNO dose was selected based on evidence of both its behavioral effectiveness and ability to inactivate terminal activity when intracranially infused over hM4Diexpressing terminals (Mahler et al., 2014). CNO was dissolved in aCSF to $100 \mu \mathrm{M}$ for ex vivo electrophysiology experiments (Stachniak et al., 2014).

\section{Ex vivo electrophysiology}

Whole-cell patch-clamp recordings were performed in brain slices from $\sim 5$ - to 6-month-old rats ( $n=8$ rats) $8-13$ weeks following AAV injection. To prepare brain slices, rats were deeply anesthetized with isoflurane and perfused transcardially with an ice-cold, oxygenated NMDG-based slicing solution containing the following (in mM): $30 \mathrm{NaHCO}_{3}, 20 \mathrm{HEPES}$, $1.25 \mathrm{NaH}_{2} \mathrm{PO}_{4}, 102 \mathrm{NMDG}, 40$ glucose, $3 \mathrm{KCl}, 0.5 \mathrm{CaCl}_{2}-2 \mathrm{H}_{2} \mathrm{O}, 10$ $\mathrm{MgSO}_{4} \mathrm{H}_{2} \mathrm{O}$ ( $\mathrm{pH}$ adjusted to 7.3-7.35, osmolality 300-310 mOsm/L).
Brains were extracted and immediately placed in ice-cold, oxygenated NMDG slicing solution. Coronal slices $(350 \mu \mathrm{m})$ were cut using a vibrating microtome (VT1000S; Leica Microsystems) and transferred to an incubating chamber containing oxygenated NMDG slicing solution warmed to $32^{\circ} \mathrm{C}-34^{\circ} \mathrm{C}$ and allowed to recover for $15 \mathrm{~min}$ before being transferred to an aCSF solution containing the following (in $\mathrm{mM}$ ): 130 $\mathrm{NaCl}, 3 \mathrm{KCl}, 1.25 \mathrm{NaH}_{2} \mathrm{PO}_{4}, 26 \mathrm{NaHCO}_{3}, 2 \mathrm{MgCl}_{2}, 2 \mathrm{CaCl}_{2}$, and 10 glucose) oxygenated with $95 \% \mathrm{O}_{2}-5 \% \mathrm{CO}_{2}$ ( $\mathrm{pH} 7.2-7.4$, osmolality $290-$ $310 \mathrm{mOsm} / \mathrm{L}, 32-34^{\circ} \mathrm{C}$ ). After $15 \mathrm{~min}$, slices were moved to room temperature and allowed to recover for an additional $\sim 30$ min before recording. All recordings were performed using an upright microscope (Olympus BX51WI) equipped with differential interference contrast optics and fluorescence imaging (QIACAM fast 1394 monochromatic camera with Q-Capture Pro software, QImaging).

Whole-cell patch-clamp recordings in voltage-clamp mode were obtained from postsynaptic BLA ( $\mathrm{OFC}_{\mathrm{hM} 4 \mathrm{Di} / \mathrm{ChR} 2} \rightarrow \mathrm{BLA}: n=5$ cells, or $\mathrm{OFC}_{\mathrm{ChR} 2} \rightarrow \mathrm{BLA}: n=5$ cells $)$ or OFC (BLA $\mathrm{BM} 4 \mathrm{Di} / \mathrm{ChR} 2 \rightarrow \mathrm{OFC}: n=7$ cells, or $\mathrm{BLA}_{\mathrm{ChR} 2} \rightarrow \mathrm{OFC}: n=5$ cells) neurons using a MultiClamp 700B Amplifier (Molecular Devices) and the pCLAMP 10.3 acquisition software. Visible eYFP-expressing terminals were identified in the OFC or BLA, and recordings were obtained from cells located only in highly fluorescent regions. The patch pipette (3-5 $\mathrm{m} \Omega$ resistance) contained a Cesium methanesulfonate-based internal recording solution (in mM) as follows: 125 Cs-methanesulfonate, $4 \mathrm{NaCl}, 1 \mathrm{MgCl}_{2}$, 5 MgATP, 9 EGTA, 8 HEPES, 1 GTP-Tris, 10 phosphocreatine, and 0.1 leupeptin ( $\mathrm{pH} 7.2$, with $\mathrm{CsOH}$, 270-280 mOsm). Biocytin (0.2\%, Sigma-Aldrich) was included in the internal recording solution for subsequent postsynaptic cell visualization and identification.

After breaking through the membrane, recordings were obtained from cells while holding the membrane potential at $-70 \mathrm{mV}$. Electrode access resistances were maintained at $<30 \mathrm{M} \Omega$. Blue light ( $470 \mathrm{~nm}, 5 \mathrm{~ms}$ pulse, $8 \mathrm{~mW}$; CoolLED) was delivered through the epifluorescence illumination pathway using Chroma Technologies filter cubes to activate ChR2 and stimulate BLA terminals in the OFC, or OFC terminals in the BLA. All voltage-clamp recordings were performed in the presence of $\mathrm{GABA}_{\mathrm{A}}$ receptor antagonists, bicuculline or gabazine $(10 \mu \mathrm{M}$, Tocris Bioscience, R\&D Systems). Optically evoked EPSCs were recorded both before and after CNO bath application (100 $\mu \mathrm{M} ; 20 \mathrm{~min})$. As an additional control, recordings were made with identical timing, but without $\mathrm{CNO}$ bath application ( $n=4$ cells $)$.

\section{Histology}

Rats in the behavior experiments were deeply anesthetized with Nembutal and transcardially perfused with PBS followed by $4 \%$ PFA. Brains were removed and postfixed in 4\% PFA overnight, placed into $30 \%$ sucrose solution, then sectioned into $30-40 \mu \mathrm{m}$ slices using a cryostat, and stored in PBS or cryoprotectant. To visualize hM4Di-mCherry expression in BLA or OFC cell bodies, free-floating coronal sections were mounted onto slides and coverslipped with ProLong Gold mounting medium with DAPI (Invitrogen). The signal for axonal expression of hM4Di-mCherry in terminal regions was immunohistochemically amplified using antibodies directed against mCherry. Floating coronal sections were washed 2 times in $1 \times$ PBS for $10 \mathrm{~min}$ and then blocked for 1-2 $\mathrm{h}$ at room temperature in a solution of $5 \%$ normal goat serum and $1 \%$ Triton X-100 dissolved in PBS. Sections were then washed 3 times in PBS for $15 \mathrm{~min}$ and then incubated in blocking solution containing rabbit anti-DsRed antibody (1:1000; Clontech) with gentle agitation at $4^{\circ} \mathrm{C}$ for $18-22 \mathrm{~h}$. Sections were next rinsed 3 times in the blocking solution and incubated in AlexaFluor-594-conjugated (red) goat secondary antibody (1:500; Invitrogen) for $2 \mathrm{~h}$. Sections were washed 3 times in PBS for 30 min, mounted on slides, and coverslipped with ProLong Gold mounting medium with DAPI. All images were acquired using a Keyence (BZX710) microscope with a $4 \times$ or $20 \times$ objective (CFI Plan Apo), CCD camera, and BZ-X Analyze software. Data from subjects for which hM4DimCherry expression could not be confirmed bilaterally in the target region were omitted from the analysis. We also confirmed that cannula placement was in the target region and coincided with labeled axon terminals.

Following ex vivo recordings, brain slices were fixed in 4\% PFA for $24 \mathrm{~h}$. Slices were then washed with $1 \times$ PBS, permeabilized with $1 \%$ 
Triton overnight at $4^{\circ} \mathrm{C}$, and incubated for $2 \mathrm{~h}$ with streptavidin-Marina Blue (365 nm, ThermoFisher Scientific) at room temperature. Fluorescent images were taken of both recorded cells and eYFP or mCherryexpressing terminals using a Zeiss Apotome equipped with $20 \times$ and $40 \times$ objectives.

\section{Experimental design and statistical analysis}

Data were processed with Microsoft Excel and then analyzed with Prism (GraphPad) and SPSS (IBM). For all hypothesis tests, the $\alpha$ level for significance was set to $p<0.05$. The behavioral data of primary interest were statistically evaluated with repeated-measures ANOVAs (GeisserGreenhouse correction). For well-established behavioral effects (PIT, devaluation, reinstatement), multiple pairwise comparisons (paired $t$ test, two-tailed) were used for a priori post hoc comparisons, as advised by Levin et al. (1994) based on a logical extension of Fisher's protected least significant difference procedure for controlling familywise Type I error rates. Bonferroni or Dunnet's corrections were used for post hoc analyses of all drug effects. Electrophysiological data were analyzed with unpaired $t$ tests.

Behavioral data were analyzed for the rate of both lever pressing and entries into food-delivery port. Both drug and test phase were withinsubject factors. All data were averaged across trials. For the PIT tests, lever pressing was averaged across levers for the 2-min baseline period and compared with that during the CS period, which was separated for presses on the lever that, during training, earned the same outcome as the cue predicted (i.e., CS-Same presses) versus those on the other available lever (i.e., CS-Different presses). Data from the reinstatement test were analyzed similarly, with reward-period presses separated for those on the lever that previously earned the same outcome as the presented reward (i.e., Reinstated presses) versus those on the alternate lever (i.e., Non-reinstated). For the PIT tests, entries into the food-delivery port were compared between the baseline and CS periods. Food-delivery port entries were analyzed similarly for the Pavlovian phase of the devaluation test; baseline entry rate was compared with entries during presentation of each CS separated for the cue that predicted the valued versus devalued reward type. Lever pressing during the instrumental phase of the devaluation test was separated for actions on the lever that, in training, earned the currently devalued versus valued reward. To specifically examine how CS presentation changed behavior during PIT and the Pavlovian devaluation test, in addition to these analyses, we also evaluated cueinduced change in lever pressing (PIT test) or food-port entries (Pavlovian devaluation test) by calculating an elevation ratio [CS responses/(CS responses + Baseline responses)].

For electrophysiological data, optically evoked EPSC amplitudes following $\mathrm{CNO}$ application were expressed as a percentage of the evoked response before CNO for comparison between AAV groups (hM4Di+ChR2 versus ChR2 only).

\section{Results}

Pathway-specific chemogenetic OFC-BLA manipulations

We used a chemogenetic approach (Armbruster et al., 2007; Smith et al., 2016) to manipulate monosynaptic $\mathrm{OFC} \rightarrow \mathrm{BLA}$ or $\mathrm{BLA} \rightarrow \mathrm{OFC}$ projections by taking advantage of the fact that DREADDs are trafficked to axon terminals where when hM4Di is activated by its otherwise inert exogenous ligand, CNO, it can attenuate presynaptic activity (Mahler et al., 2014; Stachniak et al., 2014). We first validated presynaptic suppression by terminal hM4Di activation with ex vivo electrophysiology. The $\mathrm{G}_{\mathrm{i}}$-coupled DREADD hM4Di and the excitatory opsin ChR2 were coexpressed in either the OFC (Fig. 1A) or BLA (Fig. 1D), and whole-cell patch-clamp recordings were obtained from postsynaptic cells in the ChR2and hM4Di-expressing terminal regions (Fig. $1 B, C$ ). EPSCs were evoked by blue light activation of ChR2 in both the BLA (Fig. $1 E$ ) and OFC (Fig. 1F), and the amplitude of these responses was markedly attenuated in the presence of CNO. The CNO-induced change in the optically evoked EPSC was significantly lower in both BLA $\left(t_{(8)}=5.68, p=0.0005\right)$ and $\mathrm{OFC}\left(t_{(10)}=5.41, p=\right.$
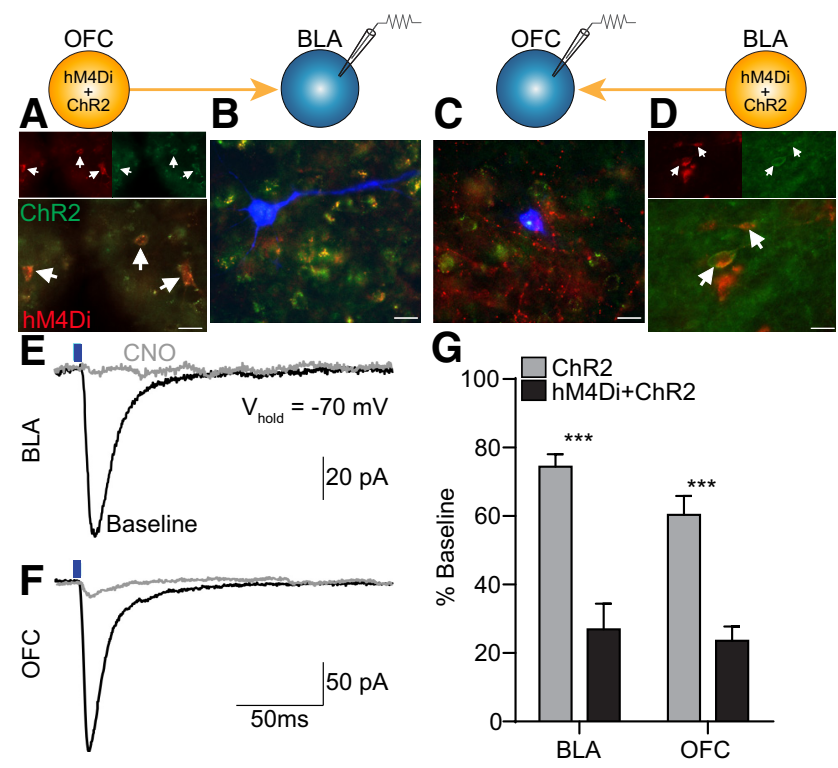

Figure 1. Effect of CNO-hM4Di inactivation of OFC $\rightarrow$ BLA or BLA $\rightarrow 0 F C$ projections on postsynaptic responses. hM4Di-mCherry and/or ChR2-EYFP were expressed in either the $\mathrm{BLA}$ or $\mathrm{OFC}$, and whole-cell patch-clamp recordings in voltage-clamp mode were obtained from postsynaptic BLA (OFC $\mathrm{hM4Di}_{\mathrm{ChR2}} \rightarrow \mathrm{BLA}: n=5$ cells; $\left.\mathrm{OFC}_{\mathrm{ChR2}} \rightarrow \mathrm{BLA}: n=5\right)$ or OFC cells $\left(\mathrm{BLA}_{\mathrm{hM} 4 \mathrm{Di} / \mathrm{ChR2}} \rightarrow\right.$ OFC: $\left.n=7 ; \mathrm{BLA}_{\mathrm{ChR2}} \rightarrow 0 \mathrm{FC}: n=5\right)$ before and after CNO application. $A$, Representative fluorescent image of hM4Di-mCherry/ChR2-eYFP expression in OFC cell bodies. Arrows indicate coexpressing cells. $\boldsymbol{B}$, Representative florescent image of biocytin-filled cell (blue) surrounded by ChR2-eYFP and hM4Di-mCherry terminals in BLA. C, Representative fluorescent image of biocytin-filled cell surrounded by ChR2-eYFP and hM4Di-mCherry terminals in OFC. $\boldsymbol{D}$, Representative fluorescent image of hM4Di-mCherry/ChR2-eYFP expression in BLA cell bodies. Scale bars, $20 \mu \mathrm{m}$. $\boldsymbol{E}$, Sample traces (average of 2-3 sweeps) of evoked EPSCs in BLA in response to optical stimulation of OFC terminals (blue line, $470 \mathrm{~nm}, 5 \mathrm{~ms}$ pulse, $8 \mathrm{~mW}$ ) before (black) and after (gray) CNO application. $F$, Sample traces of evoked EPSCs in OFC in response to optical stimulation of BLA terminals. G, Average optically evoked EPSC response following CNO, expressed as a percentage of pre-CNO baseline responses, compared between subjects expressing hM4Di and ChR2 with ChR2-only controls for recordings made in the BLA or OFC. Error bars indicate SEM. ${ }^{* * *} p<0.001$.

0.0003) slices expressing hM4Di relative to ChR2-only controls lacking this receptor (Fig. $1 G$ ). Identically timed recordings without CNO application indicated $<10 \%$ rundown of evoked EPSCs due to time alone (Average response $=98.31 \pm 4.60 \%$ SEM).

For behavioral experiments, a synapsin-driven AAV yielding $\mathrm{hM} 4 \mathrm{Di}$ expression was injected into either the $\mathrm{OFC}\left(\mathrm{OFC}_{\mathrm{hM} 4 \mathrm{Di}} \rightarrow \mathrm{BLA}\right.$ group) or BLA ( $\mathrm{BLA}_{\mathrm{hM} 4 \mathrm{Di}} \rightarrow \mathrm{OFC}$ group), yielding robust hM4Di expression (visualized by the mCherry fluorescent reporter protein; Fig. $2 A, B, G, H$ ). Guide cannulae were implanted over either the BLA (for $\mathrm{OFC}_{\mathrm{hM} 4 \mathrm{Di}} \rightarrow \mathrm{BLA}$ group) or OFC (for $\mathrm{BLA}_{\mathrm{hM} 4 \mathrm{Di}} \rightarrow \mathrm{OFC}$ group) terminal fields in close proximity to the area of axonal expression (Fig. 2C,D,E,F) to allow CNO infusion to selectively inactivate OFC terminals in the BLA or BLA terminals in the OFC. We focused on the lateral OFC subregion, which is densely connected with the BLA (Kita and Kitai, 1990; Carmichael and Price, 1995; Ongür and Price, 2000) and heavily implicated in outcome-guided conditional responding and action (Schoenbaum et al., 1998; Ostlund and Balleine, 2007b; Lucantonio et al., 2015).

\section{Contribution of $\mathrm{OFC} \rightarrow \mathrm{BLA}$ and $\mathrm{BLA} \rightarrow \mathrm{OFC}$ projections to outcome-specific Pavlovian-to-instrumental transfer} Using this approach, we examined the contribution of OFC $\rightarrow$ BLA and $\mathrm{BLA} \rightarrow \mathrm{OFC}$ projections to the ability to retrieve a stored memory of a specific predicted reward and to use this information to 


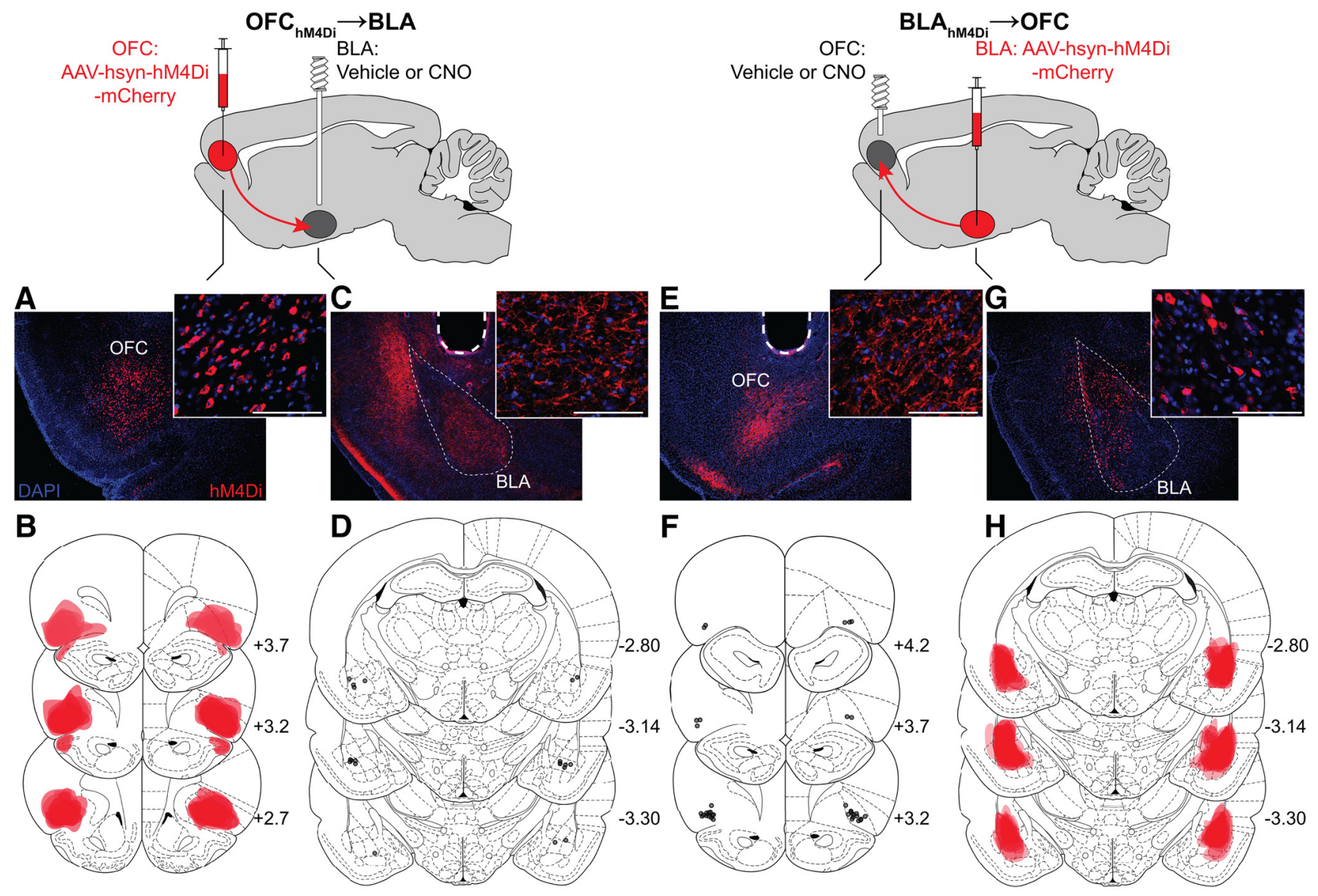

Figure 2. Viral expression and cannulae placements. $A-D, O F C_{h M 4 D i} \rightarrow B L A$ rats $(n=10)$. Bilateral hsyn-hM4Di-mCherry injections were made into the $0 \mathrm{FC}$, and guide cannulae were implanted above the BLA, such that CNO infusion would inactivate OFC terminals in the BLA. $\boldsymbol{A}$, Representative fluorescent image of hM4Di-mCherry expression in the OFC. Scale bars, $100 \mu \mathrm{m}$. $\boldsymbol{B}$, Schematic representation of hM4Di-mCherry maximal viral spread in the $\mathrm{FCC}$ for all subjects. Numbers to the bottom right of each section indicate distance anterior to bregma ( $\mathrm{mm}$ ). Coronal section drawings taken from Paxinos and Watson (1998), their Figures 6 -9 and 31-33, reprinted with permission. C, Representative immunofluorescent image of hM4Di-mCherry expression in the BLA. Dashed line indicates guide cannula track. $\boldsymbol{D}$, Schematic representation of microinfusion injector tips in the BLA. $\boldsymbol{E}-\boldsymbol{H}, \mathrm{BL} \mathrm{A}_{\mathrm{hM} 4 \mathrm{Di}} \rightarrow 0 \mathrm{FC}$ rats $(n=19)$. Bilateral $h s y n-h M 4 D i-m C h e r r y$ injections were made into the BLA, and guide cannulae were implanted above the OFC, such that CNO infusion would inactivate BLA terminals in the OFC. $E$, Representative immunofluorescent image of hM4Di-mCherry expression in the OFC. $\boldsymbol{F}$, Schematic representation of microinfusion injector tips in the OFC. $\boldsymbol{G}$, Representative fluorescent image of hM4Di-mCherry expression in the BLA. $\boldsymbol{H}$, Schematic representation of hM4Di-mCherry maximal viral spread in the BLA for all subjects.

influence reward-seeking decisions during outcome-specific PIT (Fig. 3A). Rats were trained to associate two auditory CSs with two distinct food rewards and then to earn each of those two rewards by pressing on independent levers. Rats demonstrated acquisition of the Pavlovian associations by entering the food-delivery port significantly more during the CS probe periods (Average entry rate on the final training session $\mathrm{OFC}_{\mathrm{hM} 4 \mathrm{Di}} \rightarrow \mathrm{BLA}$ group: 11.05 entries/min \pm 1.25 SEM; $\mathrm{BLA}_{\mathrm{hM} 4 \mathrm{Di}} \rightarrow \mathrm{OFC}$ group: $\left.11.89 \pm 1.51\right)$ than during the baseline periods $\left(\mathrm{OFC}_{\mathrm{hM} 4 \mathrm{Di}} \rightarrow \mathrm{BLA}\right.$ group: $4.52 \pm 0.50, t_{(9)}=$ 5.72, $p=0.0003 ; \mathrm{BLA}_{\mathrm{hM} 4 \mathrm{Di}} \rightarrow$ OFC group: $6.70 \pm 1.44, t_{(9)}=$ $4.92, p=0.0008)$. All rats also acquired the instrumental behavior (Final average press rate $\mathrm{OFC}_{\mathrm{hM} 4 \mathrm{Di}} \rightarrow \mathrm{BLA}$ group: $21.13 \pm$ 1.37 presses/min; $\mathrm{BLA}_{\mathrm{hM} 4 \mathrm{Di}} \rightarrow$ OFC group: $\left.21.45 \pm 1.54\right)$. At the critical PIT test, both levers were present, but lever pressing was not rewarded. Each CS was presented 4 times (also without accompanying reward), with intervening CS-free baseline periods, to assess its influence on action performance and selection in the novel choice scenario. Because the CSs are never associated with the instrumental actions, this test assesses the rats' ability, upon CS presentation, to retrieve a stored memory of the specific predicted reward and to use this information to motivate performance of those actions known to earn the same unique reward
(Kruse et al., 1983; Colwill and Motzkin, 1994; Gilroy et al., 2014; Corbit and Balleine, 2016).

CNO-hM4Di inactivation of OFC terminals in the BLA did not alter the expression of outcome-specific PIT (Fig. 3B; Main effect of CS Period: $F_{(2,18)}=10.18, p=0.001 ;$ Drug: $F_{(1,9)}=0.45$, $p=0.52$; CS $\times$ Drug interaction: $\left.F_{(2,18)}=0.04, p=0.96\right)$. Following either vehicle or $\mathrm{CNO}$ infusion, $\mathrm{CS}$ presentation elevated press rate selectively on the lever that, in training, earned the same predicted reward (CS-Same) relative to both pressing during the CS on the alternate available lever (CS-Different) and baseline press rate $(p=0.001-0.002)$.

CNO-hM4Di inactivation of BLA terminals in the OFC did, however, attenuate PIT expression (Fig. 3C; CS Period: $F_{(2,18)}=$ 15.64, $p=0.0001$; Drug: $F_{(1,9)}=0.63, p=0.45$; CS $\times$ Drug: $\left.F_{(2,18)}=3.54, p=0.05\right)$. Robust PIT was demonstrated under vehicle-infused control conditions; the CS elevated performance of the CS-Same action relative to both baseline $(p<0.001)$ and CS-Different pressing $(p=0.002)$. Following CNO infusion, there was no significant difference between CS-Same and either CS-Different $(p=0.15)$ or baseline pressing $(p=0.09)$, and CS-Same performance was lower following CNO relative to ve- 
A
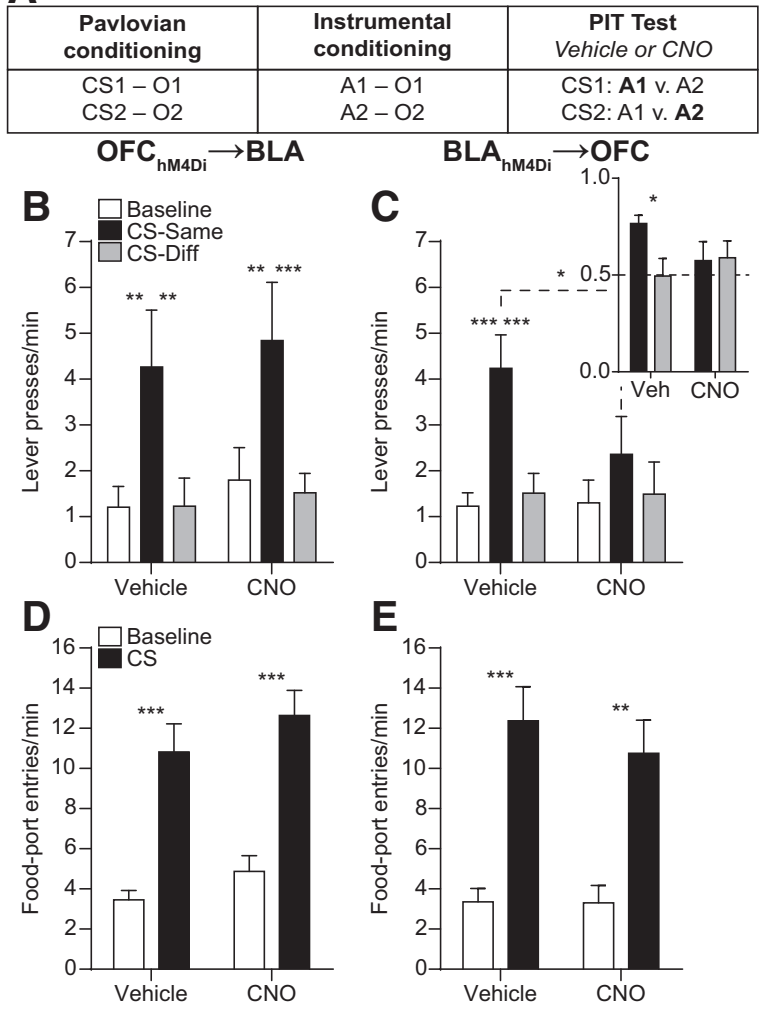

Figure 3. Effect of inactivating $\mathrm{OFC} \rightarrow \mathrm{BLA}$ or $\mathrm{BLA} \rightarrow \mathrm{OFC}$ projections on PIT. $A$, Task design. 0 , Outcome/reward; A, action. $B, C$, Trial-averaged lever presses per 2-min period averaged across both levers during the Baseline periods compared with pressing during the $C S$ periods separated for presses on the lever that, in training, delivered the same outcome as predicted by the CS (CS-Same) and pressing on the other available lever (CS-Diff) for $\mathrm{OFC}_{\mathrm{hM} 4 \mathrm{Di}} \rightarrow \mathrm{BLA}$ $(\boldsymbol{B} ; n=10)$ or BLA $\mathrm{h}_{\mathrm{hM} 4 \mathrm{Di}} \rightarrow O \mathrm{FC}(\boldsymbol{C} ; n=10)$ groups. Inset, $C$-induced elevation in responding [CS presses/(CS presses + Baseline presses)] on action Same versus Different for the $\mathrm{BLA}_{\mathrm{hM} 4 \mathrm{Di}} \rightarrow 0 \mathrm{FC}$ group. $\boldsymbol{D}, \boldsymbol{E}$, Trial-averaged entries into the food-delivery port during the Baseline and $\mathrm{CS}$ periods for the $\mathrm{OFC}_{\mathrm{hM} 4 \mathrm{Di}} \rightarrow \mathrm{BLA}(\boldsymbol{D})$ and $\mathrm{BLA}_{\mathrm{hM} 4 \mathrm{Di}} \rightarrow 0 \mathrm{FC}(\boldsymbol{E})$ groups. Error bars indicate SEM. ${ }^{*} p<0.05 .{ }^{* *} p<0.01 .{ }^{* * *} p<0.001$.

hicle $(p=0.01)$. The result was similar when the CS-induced elevation in performance on each action choice was evaluated (Fig. 3C, inset). Under control conditions, the CS induced a greater elevation in performance on action Same than action Different $\left(t_{(9)}=3.08, p=0.01\right)$, but following CNO infusion there was no significant difference between actions $\left(t_{(9)}=0.10\right.$, $p=0.92)$. The effect of inactivating BLA terminals in the OFC was restricted to cue-influenced action; lever pressing during the baseline period was not altered by $\mathrm{CNO}(p=0.90)$. CNO-hM4Di inactivation of BLA terminals in the OFC consistently attenuated PIT expression across trials $\left(\right.$ Drug $\times \mathrm{CS} \times$ Trial: $F_{(6,54)}=1.61$, $p=0.20)$.

Inactivation of neither OFC terminals in the BLA (Fig. 3D; CS Period: $F_{(1,9)}=95.95, p<0.0001$; Drug: $F_{(1,9)}=1.62, p=0.23$; CS $\times$ Drug: $\left.F_{(1,9)}=0.08, p=0.78\right)$, nor BLA terminals in the OFC (Fig. 3E; CS Period: $F_{(1,9)}=106.30, p<0.0001 ;$ Drug: $F_{(1,9)}=0.26$, $p=0.62$; CS $\times$ Drug: $\left.F_{(1,9)}=0.49, p=0.50\right)$ altered Pavlovian conditional food-port approach responding. In all cases, CS presentation significantly elevated entries into the food-delivery port $(p<$ 0.0001-0.001).

$\mathrm{CNO}$ had no effect on lever pressing during PIT in subjects lacking the hM4Di receptor when it was infused into either the BLA ( $\mathrm{OFC}_{\text {mCherry }} \rightarrow$ BLA group; Fig. $4 A$; CS Period: $F_{(2,20)}=7.07$, $p=0.005$; Drug: $F_{(1,10)}=1.04, p=0.33$; CS $\times$ Drug: $F_{(2,20)}=$
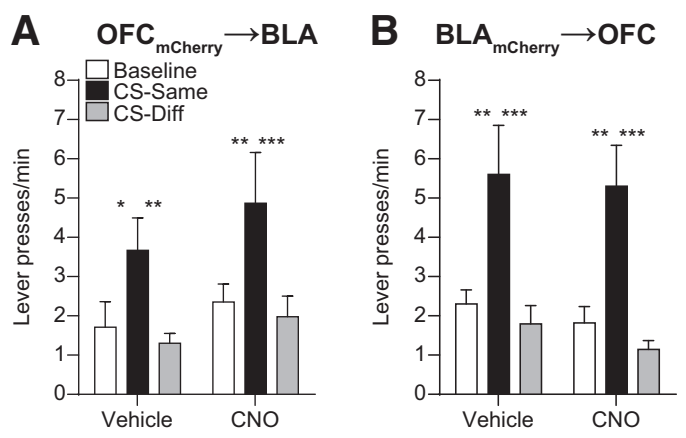

Figure 4. Effect of $\mathrm{CNO}$ infusion in subjects lacking hM4Di receptors. $A, B$, Trial-averaged lever presses per 2-min period averaged across both levers during the Baseline periods compared with pressing during the $C S$ periods separated for presses on the lever that, in training, delivered the same outcome as predicted by the CS (CS-Same) and pressing on the other available lever (CS-Diff) for $0 \mathrm{FC}_{\mathrm{mcherry}} \rightarrow \mathrm{BLA}(\boldsymbol{A} ; n=11)$ and $\mathrm{BL} A_{\mathrm{mcherry}} \rightarrow 0 \mathrm{FC}(\boldsymbol{B} ; n=12)$ groups. Error bars indicate SEM. ${ }^{*} p<0.05 .{ }^{* *} p<0.01 .{ }^{* * *} p<0.001$.

$0.20, p=0.82)$ or OFC (BLA mCherry $\rightarrow$ OFC group; Fig. $4 B$; CS Period: $F_{(2,22)}=34.21, p<0.0001$; Drug: $F_{(1,11)}=0.31, p=0.59$; CS $\times$ Drug: $\left.F_{(2,22)}=0.04, p=0.96\right)$.

\section{Contribution of BLA $\rightarrow$ OFC projections to the sensitivity of instrumental actions and Pavlovian conditional responses to outcome-specific devaluation}

The above data suggest that $\mathrm{BLA} \rightarrow \mathrm{OFC}$, but not $\mathrm{OFC} \rightarrow \mathrm{BLA}$, projections are required for a reward-predictive cue to selectively motivate performance of an action that results in the same rewarding outcome. This capacity relies upon retrieval of a representation of the specific shared reward (i.e., outcome) encoded in both the previously learned Pavlovian stimulus-outcome and instrumental action-outcome associations (Dickinson and Balleine, 2002; Corbit and Janak, 2010). The BLA is required for both types of associations (Blundell et al., 2001; Balleine et al., 2003; Ostlund and Balleine, 2008; Johnson et al., 2009). Therefore, we next asked whether BLA $\rightarrow$ OFC projections are required for reward representations triggered by either Pavlovian reward-predictive stimuli, by the rats' own knowledge of available action-outcome contingencies, or both (Fig. 5A).

A separate group of $\mathrm{BLA}_{\mathrm{hM} 4 \mathrm{Di}} \rightarrow \mathrm{OFC}$ rats were trained as described above. These subjects demonstrated acquisition of the Pavlovian associations by entering the food-delivery port significantly more during the CS probe periods $(12.22 \pm 1.08)$ than the baseline periods $\left(5.03 \pm 0.62 ; t_{(8)}=7.24, p<0.0001\right)$ and acquired the instrumental behavior (final average press rate $20.54 \pm$ 1.48). Before test, one of the food rewards was devalued by sensory-specific satiety. Rats were then given a brief unrewarded instrumental choice test followed by a test of conditional foodport approach responding, in which levers were retracted and each CS was presented 2 times (without accompanying reward), with intervening CS-free, baseline periods. Infusions were made after the sensory-specific satiety procedure, but before the test to evaluate the influence of inactivation of BLA terminals in the OFC on the retrieval of reward representations, rather than on devaluation learning per se. If rats are able to recall the learned action-outcome contingencies, then, during the instrumental phase of the test, they should be able to select the action that earns the valued reward, downshifting responding on the action that earns the devalued reward. Similarly, if the Pavlovian cues trigger the recall of a memory of their specific predicted reward, then rats should show robust conditional food-port approach responding to the cue signaling the valued reward, but attenuated responding 
A

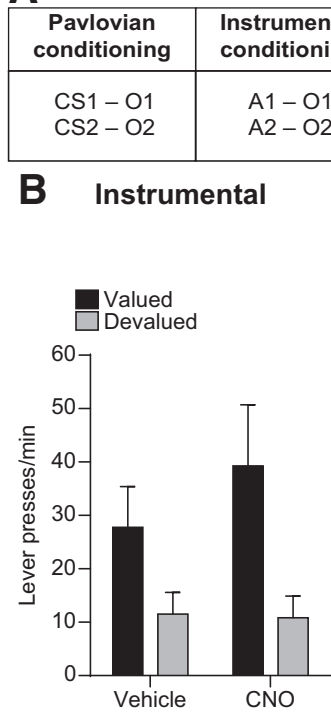

\begin{tabular}{|l|l|}
\hline Sensory- & Devaluation test
\end{tabular} specific satiety Vehicle or CNO

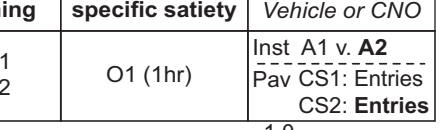

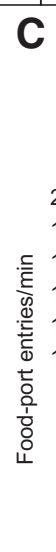

$0_{7}$ *

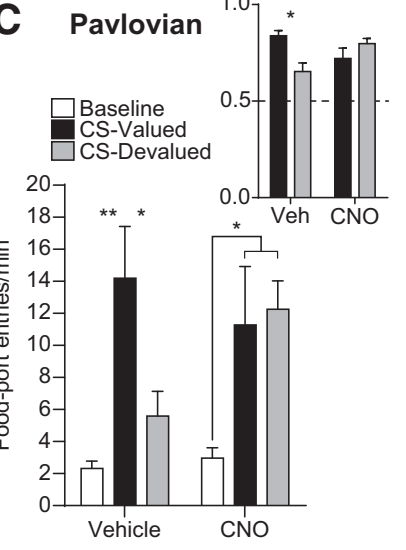

Figure 5. Effect of inactivating $B L A \rightarrow 0 F C$ projections on sensitivity to outcome-specific devaluation. $\boldsymbol{A}$, Task design. Only one devaluation condition shown. $\boldsymbol{B}$, Average lever-press rate during the devaluation test. Presses separated for those that, in training, earned the currently devalued versus valued reward type. C, Trial-averaged entries into the food-delivery port during the Baseline and CS periods separated by the CS predicted the valued versus devalued reward. Inset, CS-induced elevation in responding [CS entries/(CS entries + Baseline entries)] $(n=9)$. Error bars indicate SEM. ${ }^{*} p<0.05 .{ }^{* *} p<0.01$.

to the cue signaling the devalued reward. Because, in both cases, a specific reward expectation is needed to influence behavior, this test provided an opportunity to evaluate the contribution of $\mathrm{BLA} \rightarrow \mathrm{OFC}$ projections to the generation of detailed reward expectancies.

CNO-hM4Di inactivation of BLA terminals in the OFC was without effect on the sensitivity of instrumental choice performance to reward devaluation (Fig. 5B; Devaluation: $F_{(1,8)}=$ 13.50, $p=0.006$; Drug: $F_{(1,8)}=0.81, p=0.39$; Devaluation $\times$ Drug: $\left.F_{(1,8)}=0.31, p=0.60\right)$. Conversely, this did impair rats' ability to adjust their Pavlovian conditional food-port approach responding according to the current value of each specific predicted reward (Fig. 5C). The CS-induced elevation in food-port approach responding (Fig. $5 C$, inset; Devaluation: $F_{(1,8)}=2.78$, $p=0.13$; Drug: $F_{(1,8)}=0.30, p=0.60$; Devaluation $\times$ Drug: $\left.F_{(1,8)}=5.50, p=0.047\right)$ was higher when the CS signaled a valued reward relative to a devalued reward in the vehicle-infused condition $(p=0.047)$, but responding was equally elevated by both CSs following CNO infusion $(p=0.36)$. Indeed, following vehicle infusion, rats' food-port entries were significantly elevated above baseline by presentation of the CS previously associated with the valued reward ( $p=0.006$ ), but were not significantly elevated when the CS predicting the devalued reward was presented ( $p=0.40)$. Conversely, following CNO infusion, rats' food-port approach responding was elevated above baseline during both CSs (Valued: $p=0.03$, Devalued: $p=0.04$; Fig. $5 C$, main; Devaluation: $F_{(2,16)}=25.21, p<0.0001$; Drug: $F_{(1,8)}=$ $0.42, p=0.53$; Devaluation $\times$ Drug: $\left.F_{(2,16)}=1.65, p=0.22\right)$.

\section{Contribution of $\mathrm{BLA} \rightarrow \mathrm{OFC}$ projections to} outcome-specific reinstatement

The data show that activity in BLA $\rightarrow$ OFC projections is required when a cue-triggered reward representation is used to either selectively motivate instrumental action or to direct adaptive con-

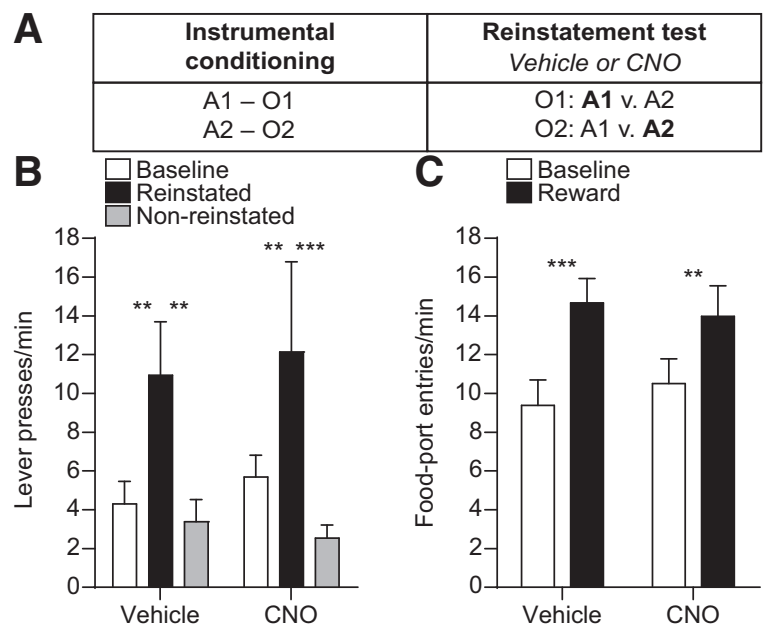

Figure 6. Effect of inactivating $B L A \rightarrow 0 F C$ projections on outcome-specific reinstatement. $\boldsymbol{A}$, Task design. $\boldsymbol{B}$, Trial-averaged lever presses per 2-min period averaged across both levers during the Baseline periods compared with pressing during the 2-min Reward periods following reward delivery, separated for presses on the lever that, in training, delivered the same outcome as the presented reward (Reinstated) and pressing on the other available lever (Nonreinstated). C, Trial-averaged entries into the food-delivery port during the Baseline and Reward-delivery periods $(n=9)$. Error bars indicate SEM. ${ }^{* *} p<0.01 .{ }^{* * *} p<0.001$.

ditional goal-approach responding. In both cases, the critical information, a predicted food reward, is not physically available, but rather must be expected based on previously learned associations. That is, the information was previously observed but is not currently observable. BLA $\rightarrow$ OFC projections may therefore participate in this reward expectation. Conversely, these projections may simply be needed for a reward, whether observable or not, to influence action. The BLA is itself required for both (Ostlund and Balleine, 2008). To test between these possibilities, we evaluated the effect of inactivation of BLA terminals in the OFC on outcome-specific reinstatement (Fig. 6A).

Rats were retrained on the instrumental contingencies (final average press rate: $31.77 \pm 2.26$ ) and then given a reinstatement test that was similar in structure to the PIT test, but with rewards themselves rather than CSs presented. During this test, rats hold the reward identity in working memory long enough to drive responding on the correct action without requiring access to a stored memory. As a result, reward presentation will selectively reinstate performance of the action that earns the same unique reward. If $\mathrm{BLA} \rightarrow \mathrm{OFC}$ projections are selectively required for the motivating influence of cueelicited expectations of unobservable rewards, then inactivation of these projections should have little effect in this task. If, however, these projections are required for a reward to selectively motivate action regardless of its physical presence, then inactivation of this pathway should impair performance.

The data support the former. CNO-hM4Di inactivation of BLA terminals in the OFC did not significantly affect the expression of outcome-specific reinstatement (Fig. 6B; Reward delivery: $F_{(2,16)}=5.49, p=0.02$; Drug: $F_{(1,8)}=0.15, p=0.71$; Reward $\times$ Drug: $\left.F_{(2,16)}=0.37, p=0.70\right)$. Following either vehicle or $\mathrm{CNO}$ infusion reward presentation selectively elevated press rate on the lever that, in training, earned the same reward type (Reinstated) relative to both pressing on the alternate available lever (Nonreinstated) and baseline press rate $(p=0.0002-0.006)$. There was also no effect on food-port entries in this task (Fig. $6 C$; Reward delivery: $F_{(1,8)}=19.32, p=0.002$; Drug: $F_{(1,8)}=0.03, p=$ 0.86; Reward $\times$ Drug: $\left.F_{(1,8)}=1.59, p=0.24\right)$. 


\section{Discussion}

Here we evaluated the contribution of $\mathrm{OFC} \rightarrow \mathrm{BLA}$ and $\mathrm{BLA} \rightarrow \mathrm{OFC}$ projections to outcome-guided behaviors. Inactivation of BLA terminals in the lateral OFC was found to disrupt the influence of cue-generated reward expectations over both instrumental action choices and Pavlovian goal-approach responses. Activity in these projections was not required when actions were guided by reward expectations based on stored action-outcome contingencies, or when rewards themselves directed action selection. BLA $\rightarrow$ OFC projections therefore enable the cue-triggered reward expectations that can motivate the execution of specific action plans and allow adaptive conditional responding.

\section{$\mathrm{BLA} \rightarrow \mathrm{OFC}$, but not $\mathrm{OFC} \rightarrow \mathrm{BLA}$, projections mediate the} selective motivating influence of reward cues over action Chemogenetic inactivation was used to evaluate the function of monosynaptic, direction-specific connections between the BLA and OFC. CNO-hM4Di activation was found to suppress terminal output through presynaptic inhibition, consistent with similar findings in other pathways (Stachniak et al., 2014; Yang et al., 2016; Zhu et al., 2016). Projection inactivation was temporally restricted to specifically assess contribution to online behavioral control. CNO-hM4Di inactivation of $\mathrm{BLA} \rightarrow \mathrm{OFC}$, but not $\mathrm{OFC} \rightarrow \mathrm{BLA}$, projections attenuated expression of outcome-specific PIT. In particular, BLA $\rightarrow$ OFC inactivation blunted the cues' ability to selectively invigorate actions directed at the same unique reward. That this manipulation did not cause the cues to nondiscriminately increase action performance and did not alter discrimination between outcomes during reinstatement argues against a simple deficit in discriminating between the CSs. Rather, activity in $\mathrm{BLA} \rightarrow \mathrm{OFC}$ projections was found to be necessary for a reward cue, by way of retrieving a representation of a specific predicted reward, to motivate specific action plans.

This result is generally consistent with findings that surgical BLA-OFC disconnection disrupts outcome-guided choice behavior (Baxter et al., 2000; Zeeb and Winstanley, 2013; Fiuzat et al., 2017) and specifically implicates monosynaptic, bottom-up $\mathrm{BLA} \rightarrow \mathrm{OFC}$ projections. It does, however, contrast to data showing that $\mathrm{OFC} \rightarrow \mathrm{BLA}$, but not $\mathrm{BLA} \rightarrow \mathrm{OFC}$, projections are necessary for cue-induced reinstatement of cocaine seeking (Arguello et al., 2017), perhaps indicating that cocaine alters recruitment of $\mathrm{OFC} \rightarrow$ BLA projections. An intact OFC is required for BLA neurons to develop associative encoding of cue-predicted rewards (Saddoris et al., 2005). OFC $\rightarrow$ BLA projections may therefore be important for stimulus-outcome encoding but not normally required once those associations have been well formed. This hypothesis warrants further investigation.

\section{$\mathrm{BLA} \rightarrow \mathrm{OFC}$ projections mediate cue-triggered reward expectancies}

Successful PIT requires retrieval of both the previously learned action-outcome and stimulus-outcome associations. Two pieces of evidence here suggest that $\mathrm{BLA} \rightarrow \mathrm{OFC}$ projections are not required for rats to access knowledge of the specific consequences of their instrumental actions. First, inactivation of BLA terminals in the OFC did not affect the ability to use the current value of specific anticipated rewards to influence instrumental choice. Second, it also left unaffected the ability of reward delivery to selectively reinstate performance of the action known to earn the same unique reward. These results could be interpreted as inconsistent with findings that BLA-OFC disconnection lesions disrupt the sensitivity of choice behavior to outcome-specific de- valuation (Baxter et al., 2000; Zeeb and Winstanley, 2013; Fiuzat et al., 2017). But, in these previous studies, OFC-BLA connectivity was disrupted throughout both the devaluation learning opportunity and the choice test (and, in some cases, the whole of training and test), unlike the present study in which, to focus on memory retrieval, BLA $\rightarrow$ OFC projections were inactivated after devaluation just before test. While $\mathrm{BLA} \rightarrow \mathrm{OFC}$ projections are not needed for value-guided instrumental choice, BLA-OFC connectivity might be necessary for learning about changes in value. This possibility is consistent with evidence that the BLA is required for value encoding (Wassum et al., 2009, 2011; Parkes and Balleine, 2013; Wassum et al., 2016).

$\mathrm{BLA} \rightarrow \mathrm{OFC}$ projections were, however, required for cuetriggered outcome expectations to influence behavior. In support of this, inactivation of BLA terminals in the OFC prevented subjects from modulating their Pavlovian conditional goal-approach responding according to the current value of the specific cuepredicted reward. The PIT deficit therefore resulted from an inability of the cue to engender a reward expectation based on a stored stimulus-outcome memory. This could also explain why BLA-OFC disconnection lesions disrupt the sensitivity of instrumental choice behavior to devaluation, given that task demands in these experiments likely required stimulus-outcome information (Baxter et al., 2000; Zeeb and Winstanley, 2013; Fiuzat et al., 2017). That BLA $\rightarrow$ OFC projections are vital for cue-triggered reward expectations is consistent with evidence that reward cues activate BLA neurons (Paton et al., 2006; Tye and Janak, 2007; Ambroggi et al., 2008; Sangha et al., 2013; Beyeler et al., 2016) and that the OFC specializes in stimulus-outcome representations (Ostlund and Balleine, 2007a, b; Rudebeck et al., 2008, 2017; Camille et al., 2011).

These projections were not, however, necessary for the general, nonspecific motivational influence of the cue. During PIT, the cue-induced elevation in goal-approach responding, which did not require a specific reward expectation because there was a single shared food port, was unaffected by inactivation of BLA $\rightarrow$ OFC projections. Moreover, following devaluation, food-port entries were elevated by the reward-predictive cue regardless of whether the specific predicted reward was devalued or not. This is consistent with evidence that the BLA is not required for expression of the general form of PIT, in which cues nondiscriminately motivate action (Corbit and Balleine, 2005; Mahler and Berridge, 2012).

The BLA has been suggested to encode motivationally salient, precise reward representations (Schoenbaum et al., 1998; Fanselow and Wassum, 2015; Wassum and Izquierdo, 2015). Such information is needed to generate expectations about the current and potential future states, or situations, that guide decision making. Both the expression of outcome-specific PIT and the sensitivity of Pavlovian conditional responses to devaluation are consistent with the subject using an internally generated state of the environment to guide behavior. In the devaluation test in particular, appropriate responding requires an understanding that, although things have not perceptually changed (e.g., CS presence), the state is nonetheless different because the specific anticipated reward is no longer valuable. The data here can therefore be interpreted as evidence that BLA $\rightarrow$ OFC projections are required when one must use a cue to generate a state expectation when the critical information, the reward, is not currently observable. In further support of this, these projections were not needed when the reward was itself present to direct action.

Although BLA $\rightarrow$ OFC projections appear to facilitate decision making, they are unlikely to mediate the actual decision-making 
process itself. Were this the case, inactivation of BLA terminals in the OFC during PIT would have resulted in a nonspecific cueinduced increase in performance of both Same and Different actions, indicating an inability to select between actions on the basis of the cue-provided expectation. Rather, BLA projections may relay currently unobservable reward-specific information to the OFC for use in making predictions about future states. Indeed, the OFC has been suggested to be important for using reward expectations to guide action (Izquierdo et al., 2004; Delamater, 2007; Balleine et al., 2011; Schoenbaum et al., 2016; Sharpe and Schoenbaum, 2016) perhaps by influencing downstream decision circuits (Keiflin et al., 2013), and lesions to this region do cause nonspecific cue-induced increases in instrumental activity during PIT (Ostlund and Balleine, 2007b). Moreover, activity in the OFC of humans (Gottfried et al., 2003; KleinFlügge et al., 2013; Howard et al., 2015; Howard and Kahnt, 2017), nonhuman primates (Rich and Wallis, 2016), and rodents (McDannald et al., 2014; Farovik et al., 2015; Lopatina et al., 2015) can represent detailed information about unobservable anticipated events. Correspondingly, OFC lesions or inactivations cause deficits in using anticipated rewarding events to guide behavior (Gallagher et al., 1999; Pickens et al., 2003, 2005; Izquierdo et al., 2004; Ostlund and Balleine, 2007b; West et al., 2011; Jones et al., 2012; Bradfield et al., 2015; Murray et al., 2015). If, as proposed (Wilson et al., 2014; Schuck et al., 2016), the OFC represents the current, not fully observable state, then the results here suggest that projections from the BLA enable rewardpredictive cues to provide the OFC with detailed expectations of potential rewards available in that state. In concordance with this, an intact BLA is needed for neuronal encoding of anticipated outcomes in the OFC in rats (Schoenbaum et al., 2003; Rudebeck et al., 2013), nonhuman primates (Rudebeck et al., 2013, 2017), and humans (Hampton et al., 2007).

\section{Implications}

Evidence suggests that the cognitive symptoms underlying many psychiatric diseases result from a failure to appropriately anticipate potential future events. Indeed, deficits in the cognitive consideration of potential rewarding events have been detected in patients diagnosed with addiction (Hogarth et al., 2013), schizophrenia (Morris et al., 2015), depression (Seymour and Dolan, 2008), and social anxiety disorder (Alvares et al., 2014). Disrupted amygdala and OFC activity and connectivity have also been associated with these diseases (Ressler and Mayberg, 2007; Price and Drevets, 2010; Goldstein and Volkow, 2011; Passamonti et al., 2012; Liu et al., 2014; Sladky et al., 2015). These data therefore have important implications for the understanding and treatment of these psychiatric conditions, and suggest that they might arise, in part, from disrupted transmission of reward information from the BLA to the OFC.

\section{References}

Alvares GA, Balleine BW, Guastella AJ (2014) Impairments in goal-directed actions predict treatment response to cognitive-behavioral therapy in social anxiety disorder. PLoS One 9:e94778. CrossRef Medline

Ambroggi F, Ishikawa A, Fields HL, Nicola SM (2008) Basolateral amygdala neurons facilitate reward-seeking behavior by exciting nucleus accumbens neurons. Neuron 59:648-661. CrossRef Medline

Arguello AA, Richardson BD, Hall JL, Wang R, Hodges MA, Mitchell MP, Stuber GD, Rossi DJ, Fuchs RA (2017) Role of a lateral orbital frontal cortex-basolateral amygdala circuit in cue-induced cocaine-seeking behavior. Neuropsychopharmacology 42:727-735. CrossRef Medline

Armbruster BN, Li X, Pausch MH, Herlitze S, Roth BL (2007) Evolving the lock to fit the key to create a family of $\mathrm{G}$ protein-coupled receptors po- tently activated by an inert ligand. Proc Natl Acad Sci U S A 104:51635168. CrossRef Medline

Balleine BW, Dickinson A (1998) Goal-directed instrumental action: contingency and incentive learning and their cortical substrates. Neuropharmacology 37:407-419. CrossRef Medline

Balleine BW, Killcross AS, Dickinson A (2003) The effect of lesions of the basolateral amygdala on instrumental conditioning. J Neurosci 23:666675. Medline

Balleine BW, Leung BK, Ostlund SB (2011) The orbitofrontal cortex, predicted value, and choice. Ann N Y Acad Sci 1239:43-50. CrossRef Medline

Baxter MG, Parker A, Lindner CC, Izquierdo AD, Murray EA (2000) Control of response selection by reinforcer value requires interaction of amygdala and orbital prefrontal cortex. J Neurosci 20:4311-4319. Medline

Beyeler A, Namburi P, Glober GF, Simonnet C, Calhoon GG, Conyers GF, Luck R, Wildes CP, Tye KM (2016) Divergent routing of positive and negative information from the amygdala during memory retrieval. Neuron 90:348-361. CrossRef Medline

Blundell P, Hall G, Killcross S (2001) Lesions of the basolateral amygdala disrupt selective aspects of reinforcer representation in rats. J Neurosci 21:9018-9026. Medline

Bradfield LA, Dezfouli A, van Holstein M, Chieng B, Balleine BW (2015) Medial orbitofrontal cortex mediates outcome retrieval in partially observable task situations. Neuron 88:1268-1280. CrossRef Medline

Camille N, Tsuchida A, Fellows LK (2011) Double dissociation of stimulusvalue and action-value learning in humans with orbitofrontal or anterior cingulate cortex damage. J Neurosci 31:15048-15052. CrossRef Medline

Carmichael ST, Price JL (1995) Limbic connections of the orbital and medial prefrontal cortex in macaque monkeys. J Comp Neurol 363:615-641. CrossRef Medline

Colwill RM, Motzkin DK (1994) Encoding of the unconditioned stimulus in Pavlovian conditioning. Anim Learn Behav 22:384-394. CrossRef

Corbit LH, Balleine BW (2005) Double dissociation of basolateral and central amygdala lesions on the general and outcome-specific forms of Pavlovianinstrumental transfer. J Neurosci 25:962-970. CrossRef Medline

Corbit LH, Balleine BW (2016) Learning and motivational processes contributing to Pavlovian-instrumental transfer and their neural bases: dopamine and beyond. Curr Top Behav Neurosci 27:259-289. CrossRef Medline

Corbit LH, Janak PH (2010) Posterior dorsomedial striatum is critical for both selective instrumental and Pavlovian reward learning. Eur J Neurosci 31:1312-1321. CrossRef Medline

Delamater AR (2007) The role of the orbitofrontal cortex in sensory-specific encoding of associations in Pavlovian and instrumental conditioning. Ann N Y Acad Sci 1121:152-173. CrossRef Medline

Delamater AR (2012) On the nature of CS and US representations in Pavlovian learning. Learn Behav 40:1-23. CrossRef Medline

Delamater AR, Oakeshott S (2007) Learning about multiple attributes of reward in Pavlovian conditioning. Ann N Y Acad Sci 1104:1-20. CrossRef Medline

Dickinson A, Balleine BW (2002) The role of learning in the operation of motivational systems. In: Learning, motivation and emotion, Volume 3 of Steven's handbook of experimental psychology, Ed 3 (Gallistel CR, ed), pp 497-533. New York: Wiley.

Fanselow MS, Wassum KM (2015) The origins and organization of vertebrate Pavlovian conditioning. Cold Spring Harb Perspect Biol 8:a021717. CrossRef Medline

Farovik A, Place RJ, McKenzie S, Porter B, Munro CE, Eichenbaum H (2015) Orbitofrontal cortex encodes memories within value-based schemas and represents contexts that guide memory retrieval. J Neurosci 35:83338344. CrossRef Medline

Fiuzat EC, Rhodes SE, Murray EA (2017) The role of orbitofrontalamygdala interactions in updating action-outcome valuations in macaques. J Neurosci 37:2463-2470. CrossRef Medline

Gallagher M, McMahan RW, Schoenbaum G (1999) Orbitofrontal cortex and representation of incentive value in associative learning. J Neurosci 19:6610-6614. Medline

Gilroy KE, Everett EM, Delamater AR (2014) Response-outcome versus outcome-response associations in Pavlovian-to-instrumental transfer: effects of instrumental training context. Int J Comp Psychol 27:585-597. Medline

Goldstein RZ, Volkow ND (2011) Dysfunction of the prefrontal cortex in 
addiction: neuroimaging findings and clinical implications. Nat Rev Neurosci 12:652-669. CrossRef Medline

Gore F, Schwartz EC, Brangers BC, Aladi S, Stujenske JM, Likhtik E, Russo MJ, Gordon JA, Salzman CD, Axel R (2015) Neural representations of unconditioned stimuli in basolateral amygdala mediate innate and learned responses. Cell 162:134-145. CrossRef Medline

Gottfried JA, O’Doherty J, Dolan RJ (2003) Encoding predictive reward value in human amygdala and orbitofrontal cortex. Science 301:11041107. CrossRef Medline

Hampton AN, Adolphs R, Tyszka MJ, O’Doherty JP (2007) Contributions of the amygdala to reward expectancy and choice signals in human prefrontal cortex. Neuron 55:545-555. CrossRef Medline

Hogarth L, Balleine BW, Corbit LH, Killcross S (2013) Associative learning mechanisms underpinning the transition from recreational drug use to addiction. Ann N Y Acad Sci 1282:12-24. CrossRef Medline

Howard JD, Kahnt T (2017) Identity-specific reward representations in orbitofrontal cortex are modulated by selective devaluation. J Neurosci 37: 2627-2638. CrossRef Medline

Howard JD, Gottfried JA, Tobler PN, Kahnt T (2015) Identity-specific coding of future rewards in the human orbitofrontal cortex. Proc Natl Acad Sci U S A 112:5195-5200. CrossRef Medline

Izquierdo A, Suda RK, Murray EA (2004) Bilateral orbital prefrontal cortex lesions in rhesus monkeys disrupt choices guided by both reward value and reward contingency. J Neurosci 24:7540-7548. CrossRef Medline

Johnson AW, Gallagher M, Holland PC (2009) The basolateral amygdala is critical to the expression of Pavlovian and instrumental outcome-specific reinforcer devaluation effects. J Neurosci 29:696-704. CrossRef Medline

Jones JL, Esber GR, McDannald MA, Gruber AJ, Hernandez A, Mirenzi A, Schoenbaum G (2012) Orbitofrontal cortex supports behavior and learning using inferred but not cached values. Science 338:953-956. CrossRef Medline

Keiflin R, Reese RM, Woods CA, Janak PH (2013) The orbitofrontal cortex as part of a hierarchical neural system mediating choice between two good options. J Neurosci 33:15989-15998. CrossRef Medline

Kita H, Kitai ST (1990) Amygdaloid projections to the frontal cortex and the striatum in the rat. J Comp Neurol 298:40-49. CrossRef Medline

Klein-Flügge MC, Barron HC, Brodersen KH, Dolan RJ, Behrens TE (2013) Segregated encoding of reward-identity and stimulus-reward associations in human orbitofrontal cortex. J Neurosci 33:3202-3211. CrossRef Medline

Kruse H, Overmier J, Konz W, Rokke E (1983) Pavlovian conditioned stimulus effects upon instrumental choice behavior are reinforcer specific. Learn Motiv 14:165-181. CrossRef

Levin JR, Serlin RC, Seaman MA (1994) A controlled powerful multiplecomparison strategy for several situations. Psychol Bull 115:153-159. CrossRef

Liu H, Tang Y, Womer F, Fan G, Lu T, Driesen N, Ren L, Wang Y, He Y, Blumberg HP, Xu K, Wang F (2014) Differentiating patterns of amygdala-frontal functional connectivity in schizophrenia and bipolar disorder. Schizophr Bull 40:469-477. CrossRef Medline

Lopatina N, McDannald MA, Styer CV, Sadacca BF, Cheer JF, Schoenbaum G (2015) Lateral orbitofrontal neurons acquire responses to upshifted, downshifted, or blocked cues during unblocking. Elife 4:e11299. CrossRef Medline

Lucantonio F, Gardner MP, Mirenzi A, Newman LE, Takahashi YK, Schoenbaum G (2015) Neural estimates of imagined outcomes in basolateral amygdala depend on orbitofrontal cortex. J Neurosci 35:16521-16530. CrossRef Medline

Machado CJ, Bachevalier J (2007) The effects of selective amygdala, orbital frontal cortex or hippocampal formation lesions on reward assessment in nonhuman primates. Eur J Neurosci 25:2885-2904. CrossRef Medline

Mahler SV, Berridge KC (2012) What and when to "want?" Amygdalabased focusing of incentive salience upon sugar and sex. Psychopharmacology (Berl) 221:407-426. CrossRef Medline

Mahler SV, Vazey EM, Beckley JT, Keistler CR, McGlinchey EM, Kaufling J, Wilson SP, Deisseroth K, Woodward JJ, Aston-Jones G (2014) Designer receptors show role for ventral pallidum input to ventral tegmental area in cocaine seeking. Nat Neurosci 17:577-585. CrossRef Medline

Malvaez M, Greenfield VY, Wang AS, Yorita AM, Feng L, Linker KE, Monbouquette HG, Wassum KM (2015) Basolateral amygdala rapid glutamate release encodes an outcome-specific representation vital for reward-predictive cues to selectively invigorate reward-seeking actions. Sci Rep 5:12511. CrossRef Medline

McDannald MA, Esber GR, Wegener MA, Wied HM, Liu TL, Stalnaker TA, Jones JL, Trageser J, Schoenbaum G (2014) Orbitofrontal neurons acquire responses to 'valueless' Pavlovian cues during unblocking. Elife 3:e02653. CrossRef Medline

Morris RW, Quail S, Griffiths KR, Green MJ, Balleine BW (2015) Corticostriatal control of goal-directed action is impaired in schizophrenia. Biol Psychiatry 77:187-195. CrossRef Medline

Murray EA, Moylan EJ, Saleem KS, Basile BM, Turchi J (2015) Specialized areas for value updating and goal selection in the primate orbitofrontal cortex. Elife 4:e11695. CrossRef Medline

Ongür D, Price JL (2000) The organization of networks within the orbital and medial prefrontal cortex of rats, monkeys and humans. Cereb Cortex 10:206-219. CrossRef Medline

Ostlund SB, Balleine BW (2007a) The contribution of orbitofrontal cortex to action selection. Ann N Y Acad Sci 1121:174-192. CrossRef Medline

Ostlund SB, Balleine BW (2007b) Orbitofrontal cortex mediates outcome encoding in Pavlovian but not instrumental conditioning. J Neurosci 27:4819-4825. CrossRef Medline

Ostlund SB, Balleine BW (2008) Differential involvement of the basolateral amygdala and mediodorsal thalamus in instrumental action selection. J Neurosci 28:4398-4405. CrossRef Medline

Parkes SL, Balleine BW (2013) Incentive memory: evidence the basolateral amygdala encodes and the insular cortex retrieves outcome values to guide choice between goal-directed actions. J Neurosci 33:8753-8763. CrossRef Medline

Passamonti L, Fairchild G, Fornito A, Goodyer IM, Nimmo-Smith I, Hagan CC, Calder AJ (2012) Abnormal anatomical connectivity between the amygdala and orbitofrontal cortex in conduct disorder. PLoS One 7:e48789. CrossRef Medline

Paton JJ, Belova MA, Morrison SE, Salzman CD (2006) The primate amygdala represents the positive and negative value of visual stimuli during learning. Nature 439:865-870. CrossRef Medline

Paxinos G, Watson C (1998) The rat brain in stereotaxic coordinates, Ed 4. San Diego: Academic.

Pickens CL, Saddoris MP, Setlow B, Gallagher M, Holland PC, Schoenbaum G (2003) Different roles for orbitofrontal cortex and basolateral amygdala in a reinforcer devaluation task. J Neurosci 23:11078-11084. Medline

Pickens CL, Saddoris MP, Gallagher M, Holland PC (2005) Orbitofrontal lesions impair use of cue-outcome associations in a devaluation task. Behav Neurosci 119:317-322. CrossRef Medline

Price JL (2007) Definition of the orbital cortex in relation to specific connections with limbic and visceral structures and other cortical regions. Ann N Y Acad Sci 1121:54-71. CrossRef Medline

Price JL, Drevets WC (2010) Neurocircuitry of mood disorders. Neuropsychopharmacology 35:192-216. CrossRef Medline

Ressler KJ, Mayberg HS (2007) Targeting abnormal neural circuits in mood and anxiety disorders: from the laboratory to the clinic. Nat Neurosci 10:1116-1124. CrossRef Medline

Rhodes SE, Murray EA (2013) Differential effects of amygdala, orbital prefrontal cortex, and prelimbic cortex lesions on goal-directed behavior in rhesus macaques. J Neurosci 33:3380-3389. CrossRef Medline

Rich EL, Wallis JD (2016) Decoding subjective decisions from orbitofrontal cortex. Nat Neurosci 19:973-980. CrossRef Medline

Rudebeck PH, Behrens TE, Kennerley SW, Baxter MG, Buckley MJ, Walton ME, Rushworth MF (2008) Frontal cortex subregions play distinct roles in choices between actions and stimuli. J Neurosci 28:13775-13785. CrossRef Medline

Rudebeck PH, Mitz AR, Chacko RV, Murray EA (2013) Effects of amygdala lesions on reward-value coding in orbital and medial prefrontal cortex. Neuron 80:1519-1531. CrossRef Medline

Rudebeck PH, Ripple JA, Mitz AR, Averbeck BB, Murray EA (2017) Amygdala contributions to stimulus-reward encoding in the macaque medial and orbital frontal cortex during learning. J Neurosci 37:21862202. CrossRef Medline

Saddoris MP, Gallagher M, Schoenbaum G (2005) Rapid associative encoding in basolateral amygdala depends on connections with orbitofrontal cortex. Neuron 46:321-331. CrossRef Medline

Sangha S, Chadick JZ, Janak PH (2013) Safety encoding in the basal amygdala. J Neurosci 33:3744-3751. CrossRef Medline 
Scarlet J, Delamater AR, Campese V, Fein M, Wheeler DS (2012) Differential involvement of the basolateral amygdala and orbitofrontal cortex in the formation of sensory-specific associations in conditioned flavor preference and magazine approach paradigms. Eur J Neurosci 35:1799-1809. CrossRef Medline

Schoenbaum G, Chiba AA, Gallagher M (1998) Orbitofrontal cortex and basolateral amygdala encode expected outcomes during learning. Nat Neurosci 1:155-159. CrossRef Medline

Schoenbaum G, Setlow B, Saddoris MP, Gallagher M (2003) Encoding predicted outcome and acquired value in orbitofrontal cortex during cue sampling depends upon input from basolateral amygdala. Neuron 39: 855-867. CrossRef Medline

Schoenbaum G, Chang CY, Lucantonio F, Takahashi YK (2016) Thinking outside the box: orbitofrontal cortex, imagination, and how we can treat addiction. Neuropsychopharmacology 41:2966-2976. CrossRef Medline

Schuck NW, Cai MB, Wilson RC, Niv Y (2016) Human orbitofrontal cortex represents a cognitive map of state space. Neuron 91:1402-1412. CrossRef Medline

Seymour B, Dolan R (2008) Emotion, decision making, and the amygdala. Neuron 58:662-671. CrossRef Medline

Sharpe MJ, Schoenbaum G (2016) Back to basics: making predictions in the orbitofrontal-amygdala circuit. Neurobiol Learn Mem 131:201-206. CrossRef Medline

Sladky R, Höflich A, Küblböck M, Kraus C, Baldinger P, Moser E, Lanzenberger R, Windischberger C (2015) Disrupted effective connectivity between the amygdala and orbitofrontal cortex in social anxiety disorder during emotion discrimination revealed by dynamic causal modeling for FMRI. Cereb Cortex 25:895-903. CrossRef Medline

Smith KS, Bucci DJ, Luikart BW, Mahler SV (2016) DREADDS: use and application in behavioral neuroscience. Behav Neurosci 130:137-155. CrossRef Medline

Stachniak TJ, Ghosh A, Sternson SM (2014) Chemogenetic synaptic silencing of neural circuits localizes a hypothalamus $\rightarrow$ midbrain pathway for feeding behavior. Neuron 82:797-808. CrossRef Medline

Takahashi YK, Chang CY, Lucantonio F, Haney RZ, Berg BA, Yau HJ, Bonci A, Schoenbaum G (2013) Neural estimates of imagined outcomes in the orbitofrontal cortex drive behavior and learning. Neuron 80:507-518. CrossRef Medline

Tye KM, Janak PH (2007) Amygdala neurons differentially encode motivation and reinforcement. J Neurosci 27:3937-3945. CrossRef Medline

Wassum KM, Izquierdo A (2015) The basolateral amygdala in reward learning and addiction. Neurosci Biobehav Rev 57:271-283. CrossRef Medline

Wassum KM, Ostlund SB, Maidment NT, Balleine BW (2009) Distinct opioid circuits determine the palatability and the desirability of rewarding events. Proc Natl Acad Sci U S A 106:12512-12517. CrossRef Medline

Wassum KM, Cely IC, Balleine BW, Maidment NT (2011) Micro-opioid receptor activation in the basolateral amygdala mediates the learning of increases but not decreases in the incentive value of a food reward. J Neurosci 31:1583-1599. CrossRef Medline

Wassum KM, Greenfield VY, Linker KE, Maidment NT, Ostlund SB (2016) Inflated reward value in early opiate withdrawal. Addict Biol 21:221-233. CrossRef Medline

Wellman LL, Gale K, Malkova L (2005) GABAA-mediated inhibition of basolateral amygdala blocks reward devaluation in macaques. J Neurosci 25:4577-4586. CrossRef Medline

West EA, DesJardin JT, Gale K, Malkova L (2011) Transient inactivation of orbitofrontal cortex blocks reinforcer devaluation in macaques. J Neurosci 31:15128-15135. CrossRef Medline

Wilson RC, Takahashi YK, Schoenbaum G, Niv Y (2014) Orbitofrontal cortex as a cognitive map of task space. Neuron 81:267-279. CrossRef Medline

Yang Y, Liu DQ, Huang W, Deng J, Sun Y, Zuo Y, Poo MM (2016) Selective synaptic remodeling of amygdalocortical connections associated with fear memory. Nat Neurosci 19:1348-1355. CrossRef Medline

Zeeb FD, Winstanley CA (2013) Functional disconnection of the orbitofrontal cortex and basolateral amygdala impairs acquisition of a rat gambling task and disrupts animals' ability to alter decision-making behavior after reinforcer devaluation. J Neurosci 33:6434-6443. CrossRef Medline

Zhu Y, Wienecke CF, Nachtrab G, Chen X (2016) A thalamic input to the nucleus accumbens mediates opiate dependence. Nature 530:219-222. CrossRef Medline 